Geliş tarihi / Received: 25.12 .2020

Araştırma Makalesi / Research Article

\author{
Kabul tarihi / Accepted: 10.03.2021
}

Atıf İçin: Koçak B, 2021. Camsı Karbon Elektrot ve Nafyon-Grafenle Modifiye Edilmiş Camsı Karbon Elektrot Üzerinde Ethalfluralinin Voltametrik Tayini. Iğdır Üniversitesi Fen Bilimleri Dergisi, 11(3):2112-2121.

To Cite: Koçak B, 2021. Voltammetric Determination of Ethalfularin on Glassy Carbon Electrode and Nafion-Graphene Modified Glassy Carbon Electrode. Journal of the Institute of Science and Technology, 11(3):2112-2121.

\title{
Camsı Karbon Elektrot ve Nafyon-Grafenle Modifiye Edilmiş Camsı Karbon Elektrot Üzerinde Ethalfluralinin Voltametrik Tayini
}

\section{Berna $\mathrm{KOÇAK}^{1 *}$}

ÖZET:Bu çalışmada, dinitroanilin grubu bir herbisit olan ethalfluralinin(ETF), camsı karbon elektrot(CKE) ve nafyon-grafenle modifiye edilmiş camsı karbon elektrot(N-GR/CKE) üzerindeki elektrokimyasal davranışı dönüşümlü voltametri (DV) yöntemiyle araştırıldı. ETF'nin voltametrik tayini diferansiyel puls voltametrisi(DPV) yöntemiyle incelendi. ETF'nin DPV yöntemiyle pH 7 fosfat tamponunda 0 ile $-1.5 \mathrm{~V}$ arasında CKE ile yapılan potansiyel taramasında $-0.942 \mathrm{~V}$ (1.pik akımı),-0.768V (2.pik akımı ); N-GR/CKE ile yapılan potansiyel taramasında ise $-0.674 \mathrm{~V}(1$.pik akımı ), $-0.563 \mathrm{~V}$ (2.pik akımı) görüldü. ETF'nin CKE ve N-GR/CKE üzerindeki optimum deney şartları belirlendikten sonra, kalibrasyon doğrusu, çalışma aralığı, tayin edilebilme sınırı, gözlenebilme sınırı, gün içi ve günler arası tekrar edilebilirlikleri belirlendi. Bunun yanında N-GR/CKE üzerinde ETF'ye etki eden bazı katyonların $\left(\mathrm{Cu}^{2+}, \mathrm{Ni}^{2+}, \mathrm{Co}^{2+}, \mathrm{Ca}^{2+}, \mathrm{Pb}^{2+}\right)$ girişim etkisi incelenmiştir. Elde edilen sonuçlar ETF'nin CKE ve NGR/CKE üzerinde gerçek numunelerde (toprak, su) uygulanabileceğini göstermektedir.

Anahtar Kelimeler: Ethalfluralin, Dinitroanilin, Herbisit, Nafyon-Grafen, Voltametri

\section{Voltammetric Determination of Ethalfularin on Glassy Carbon Electrode and Nafion-Graphene Modified Glassy Carbon Electrode}

ABSTRACT: In this study, the electrochemical behavior of ethalfluraline (ETF), a dinitroaniline group herbicide, on glassy carbon electrode(CKE) and nafion-graphene modified glassy carbon electrode(N-GR /CKE) was investigated by cyclic voltammetry $(\mathrm{CV})$. Voltammetric determination of ETF was examined by differential pulse voltammetry(DPV). Two peaks observed at $-0.942 \mathrm{~V}\left(1^{\text {st }}\right.$ peak current $)$ and $-0.768 \mathrm{~V}\left(2^{\text {nd }}\right.$ peak current $)$ during the potential scan of EFT by DPV method in $\mathrm{pH} 7$ phosphate buffer solution between 0 and $-1.5 \mathrm{~V}$ on CKE and at -0.674 $\mathrm{V}\left(1^{\text {st }}\right.$ peak current $)$ and $-0.563 \mathrm{~V}\left(2^{\text {nd }}\right.$ peak current $)$ during the potential scan on N-GR/CKE. After determining the optimum experimental conditions of ETF on CKE and N-GR /CKE, calibration line, working range, limit of detection(LOD), limit of quantification(LOQ), intra-day and inter-day repeatability were determined. In addition, the interference effect of some cations $\left(\mathrm{Cu}^{2+}, \mathrm{Ni}^{2+}, \mathrm{Co}^{2+}, \mathrm{Ca}^{2+}, \mathrm{Pb}^{2+}\right)$ on N-GR/CKE was also investigated.The results show that EFT can be determined in real samples(water and soil) using CKE and N-GR/CKE.

Keywords: Ethalfluralin, Dinitroaniline, Herbicide, Nafion-Graphene, Voltammetry

1 Berna KOÇAK (Orcid ID: 0000-0002-2398-1492), Munzur Üniversitesi, Tunceli Meslek Yüksekokulu, Kimya ve Kimyasal İşlemeler Teknolojisi Bölümü, Laboratuvar Teknolojisi Programı, Tunceli, Türkiye

*Sorumlu Yazar/Corresponding Author: Berna KOÇAK, e-mail: bernakocak@munzur.edu.tr/berna.kocak@hotmail.com

Makale 07/12/2018-09/12/2018 tarihleri arasında Erzurum'da gerçekleşen 4. Uluslararası Mesleki ve Teknik Bilimler Kongresinde "Nafion-Grafen ile Modifiye Edilmiş Camsı Karbon Elektrot Kullanılarak Ethalfluralinin Elektrokimyasal Davranışının İncelenmesi” poster olarak sunulmuştur.

Makale 24/10/2018-26/10/2018 tarihleri arasında Adana'da gerçekleşen $3^{\text {rd }}$ International Mediterranean Science and Engineering Kongresinde "Investigation of Electroctrochemical Behaviours of Ethalfluralin by Differantial Pulse Voltammetry Method Using Glassy Carbon Electrode” poster olarak sunulmuştur. 


\section{GİRIŞ}

Dinitroanilinler, tarımsal uygulamalarda, geniş yapraklı ve büyük yıllık otların kontrolünde çiçeklenme öncesi ve sonrasında kullanılan bir herbisit grubudur (Abdallah, 2020). Yaygın kullanımları ve uzun süreli kalıcılıklarından dolayı toprak ve yüzey suyunda bulunur (Amir ve ark.,2019) ve insan sağlığını ciddi bir şekilde etkiler (Xia ve ark., 2014). Ethalfluralin (N-etil-N- (2metil-2-propenil) 2,6-dinitro-4- (triflorometil) benzenamin) (ETF), soya, kuru fasulye, kuru bezelye, ayçiçeği, fıstık, kabak ve kanolada kullanılan dinitroanilin grubu bir herbisittir (Thriveni ve ark.,2009).

ETF'nin tayini kromatografik yöntemlerle yapılmıştır (West ve ark.,1988; Shackelford ve ark., 2000; Abdallah, 2020). Kromatografik yöntemlerin dezavantajları, oldukça zaman alıcı, tayin için uzman kişilere ihtiyaç duyulması, pahalı ve karmaşık cihazlar gerektirmesidir. Kromatografik yöntemler aksine, elektrokimyasal yöntemlerle seçici, yüksek hassasiyetli, ucuz ve kısa zamanda sonuçlar elde edilebilir (Kang ve ark.,2010). Literatürde ETF'nin voltametrik davranışı sadece asılı damla civa elektrodu ile incelenmiştir (Thriveni ve ark., 2009). Civa bazlı elektrotlar (asılı damla cıva elektrotu ve cıva film elektrot) mükemmel tekrarlanabilirlik ve yüksek hassasiyete sahiptir (Li ve ark., 2009). Fakat cıvanın toksisitesi ve ekolojik sorunlardan dolayı çevre dostu elektrotlara yönelinmiştir (Gerent ve ark., 2021). Bu nedenle çalışmada ETF'nin tayini için CKE ve N-GR/CKE kullanılmıştır.

Grafen (GR), iki boyutlu, altıgen bir konfigürasyonda sp²-bağlı karbon atomudur (Novoselov ve ark, 2004; Geim ve Novoselov, 2010). GR, teorik olarak geniş yüzey alanı, yüksek içsel mobilite, termal iletkenlik, optik geçirgenlik ve iyi elektiriksel iletkenlikten dolayı potansiyel uygulamalarında dikkat çekici bir malzemedir (Pumera ve ark., 2010; Zhu ve ark., 2010; Ntsendwana ve ark., 2012). Son zamanlarda, yapılan çalışmalar GR'nin mükemmel elektrokimyasal katalitik aktiviteye ve performansa sahip yeni bir elektrot malzemesi olduğunu göstermiştir (Yin ve ark., 2010).

Nafyon (N), sülfatlanmış bir katyon değiştirme polimeri olup, elektrostatik etkileşim yoluyla pozitif yüklü ilaçların veya iyonların seçici bir şekilde birikmesini sağlar. Bundan dolayı elektrot ara yüzünün seçiciliğini ve hassasiyetini artırır (Gao ve ark., 2016). Bunlara ilaveten modifiye edilmiş tabakanın stabilitesini sağlar (Gao ve ark., 2016; Lu ve ark., 2018). Bu özelliklerinden dolayı N, elektrotların modifiye edilmesinde yaygın bir şekilde kullanılır (Kalambate ve ark., 2015; Gao ve ark., 2016; Saidi ve ark., 2016).

GR, sulu çözelti içerisinde geri dönüşümsüz olarak topaklaşma oluşturma ve hatta güçlü $\pi-\pi$ istifleme ve van der Waal'ın etkileşimi yoluyla grafit oluşturma eğilimindedir bu GR'nin benzersiz özelliğinin ortaya çıkmasını engeller. Bunu önlemek için dağıtıcı olarak, bu çalışmada sülfatlanmış bir katyon değiştirme polimeri olan, nafyon kullanılmıştır (Li ve ark.,2009; Yin ve ark., 2010; Gao ve ark., 2016). Bu çalışmada ETF'nin elektrokimyasal davranışının incelenmesi ve voltametrik tayini CKE ve nafyon-grafenle modifiye edilmiş camsı karbon elektrot(N-GR/CKE) üzerinde yapılmıştır. Litaratürde bu elektrotlar üzerinde yapılan ETF'nin elektrokimyasal çalışmasına rastlanmamıştır.

\section{MATERYAL VE METOT}

Voltametrik ölçümler, İvıum Pocketstat potansiyotatla (potentiostat/galvanostat impedance analyzer) yapıldı ve ivıum yazılımı ile sonuçlar değerlendirilmiştir. Stok ethalfluralin ve tampon çözeltilerin hazırlanmasında, milliporedirect-3DQ marka cihazdan alınan, ultra saf su kullanılmıştır. Elektrotların yüzey temizliği alümina ile yapılmıştır. Deneysel çalışmalarda çalışma elektrodu olarak CKE (CHI104) ve N-GR/CKE, refarans elektrot olarak Ag/AgCI (3 M NaCI) elektrot (MF-2052, BASİ), karşıt elektrot olarak ise Pt tel kullanılmıştır. 
Çalışmalar sırasında kullanılan bütün kimyasallar (asetonitril $\left(\mathrm{CH}_{3} \mathrm{CN}\right)$, sodyum hidroksit $(\mathrm{NaOH})$, sülfürik asit $\left(\mathrm{H}_{2} \mathrm{SO}_{4}\right)$, hidroklorik asit $(\mathrm{HCI})$, sodyum hidrojen fosfat dihidrat $\left(\mathrm{Na}_{2} \mathrm{HPO}_{4} \cdot 2 \mathrm{H}_{2} \mathrm{O}\right)$, sodyum dihidrojen fosfat $\left(\mathrm{NaH}_{2} \mathrm{PO}_{4} \cdot 2 \mathrm{H}_{2} \mathrm{O}\right)$, kalsiyum klorür dihidrat $\left(\mathrm{CaCI}_{2} \cdot 2 \mathrm{H}_{2} \mathrm{O}\right)$, kurşun nitrat $\left(\mathrm{Pb}\left(\mathrm{NO}_{3}\right)_{2}\right)$, nikel nitrat hekza hidrat $\left.\left(\mathrm{Ni}\left(\mathrm{NO}_{3}\right)\right)_{2} .6 \mathrm{H}_{2} \mathrm{O}\right)$, kobalt nitrat $\left(\mathrm{Co}\left(\mathrm{NO}_{3}\right)_{2}\right)$, ve bakır nitrat trihidrat $\left(\mathrm{Cu}\left(\mathrm{NO}_{3}\right)_{2} .3 \mathrm{H}_{2} \mathrm{O}\right)$ merck markasından temin edildi ve herhangi bir saflaştırma işlemi uygulanmamıştır.Bu çalışmada elektrot yüzeyinin modifikasyonunda kullanılan GR iki aşamalı kimyasal yolla hazırlanmıştır. İlk aşamada Hummers yöntemiyle grafitten grafen oksit, ikinci aşamada ise grafen oksittin sodyum bor hidrürle indirgenmesiyle GR elde edilmiştir. Grafen oksit ve GR'nin karakterizasyonu FT-IR, AFM ve TEM ile yapılmıştır (Kocak ve ark.,2015). Stok ETF 1.0×10²M konsantrasyonunda, asetonitril içerisinde hazırland 1 ve $+4^{\circ} \mathrm{C}$ ' de muhafaza edilmiştir.

ETF'nin çalışma ortamının belirlenmesi diferansiyel puls voltametrisi (DPV) yöntemiyle pH 113 aralığında yapılmıştır. $\mathrm{pH} 1$ için $0.1 \mathrm{M} \mathrm{H}_{2} \mathrm{SO}_{4}$ çözeltisi, pH 2 için $0.01 \mathrm{M} \mathrm{H}_{2} \mathrm{SO}_{4}$ çözeltisi, pH 3-12 için fosfat tamponu ve pH 13 için $0.1 \mathrm{M} \mathrm{NaOH}$ çözeltisi kullanılmıştır. ETF'nin voltametrik davranışı ve CKE ve N-GR/CKE üzerinde DV yöntemiyle araştırılmıştır. ETF'nin voltametrik tayini ise CKE ve $\mathrm{N}-\mathrm{GR} / \mathrm{CKE}$ üzerinde DPV yöntemiyle yapılmıştır.

\section{N-GR/CKE Hazırlanması}

$1.0 \mathrm{mg} \mathrm{mL}^{-1} \mathrm{GR}$ içerisine $\% 25$ oranında nafyon( $1 \mathrm{wt} \%$ ) ilave edildi ve $30 \mathrm{dk}$ boyunca ultrasonik banyoda sonike edilerek homojen bir süspansiyon elde edilmiştir. Bu süspansiyondan $5.0 \mu \mathrm{L}$ alınarak yüzeyi alüminyum oksit (alümina, $\mathrm{Al}_{2} \mathrm{O}_{3}, 0.05 \mu \mathrm{m}$ ) ile temizlenmiş CKE yüzeyine damlatıldı ve oda şartlarında çözücü uzaklaştırılarak N-GR/CKE hazırlanmıştır.

\section{BULGULAR VE TARTIŞMA}

\section{Ethalfluralinin Çalışma Ortamının Belirlenmesi}

ETF'nin çalışma ortamı, CKE üzerinde, DPV yöntemiyle pik akımının pH ile değişimi incelenerek belirlenmiştir (Şekil 1). Bu amaçla pH1 için $0.1 \mathrm{M} \mathrm{H}_{2} \mathrm{SO}_{4}$ çözeltisi, pH 2 için $0.01 \mathrm{M}$ $\mathrm{H}_{2} \mathrm{SO}_{4}$ çözeltisi, pH 3-12 için fosfat tamponu ve pH 13 için $0.1 \mathrm{M} \mathrm{NaOH}$ çözeltisi kullanılmıştır. ETF'nin pH 1-3 arasında bir tane indigenme piki görülürken, $\mathrm{pH}$ 4-13 arasında iki tane indirgeme piki görülmüştür. Nitro grubunun indirgenmesi pestisitin yapısına, elektroda ve çalışma ortamına bağlı farklılıklar göstermektedir. Nitroaromatik bileşikler civa elektrot üzerinde indirgenmesi asidik ortamda iki adımda, nötr ortamda tek adımda ve alkali ortamda iki adımda gerçekleşir. Buna bağlı olarak alkali ortamda bu iki adıma karşılık gelen iki tepe noktası gözlenmiştir (Gajdar ve ark.,2016). ETF'nin 1. pik akımının $\mathrm{pH}$ ile değişimi incelendiğinde en yükssek pik akımı $\mathrm{pH} 7$ fosfat tamponunda görülmüştür (Şekil 1). Bundan sonraki bütün deneysel çalışmalarda pH 7 fosfat tamponu kullanılmıştır.

\section{ETF'nin CKE ve N-GR/CKE üzerindeki elektrokimyasal davranışının incelenmesi}

ETF'nin elektrokimyasal davranışı, pH7.0 fosfat tamponunda, CKE ve N-/GR-CKE üzerinde DV yöntemiyle incelenmiştir. ETF'in, CKE ve N-GR/CKE üzerinde iyi tanımlanmış iki indirgenme piki belirlendi. GCE üzerinde ETF'nin indirgenme pikleri -0.844V (1.pik) (6.66 $\mu \mathrm{A})$ ve -0.768 V (2.pik) $(7.97 \mu \mathrm{A})$ 'ta, N-GR/GCE üzerinde $-0.798 \mathrm{~V}$ (1.pik) $(10.4 \mu \mathrm{A})$ ve $-0.724 \mathrm{~V}$ (2.pik) (9.16 $\mu \mathrm{A}$ )'ta görülmüştür. ETF'nin DV yöntemiyle GCE üzerindeki voltamogramları, N-GR/CKE üzerinde alınan voltamogramı ile karşılaştırıldı̆̆ında pik potansiyelinin N-GR/CKE'ta pozitif yöne kaydığ gözlenmiştir. ETF'nin CKE'taki pik akımları, N-GR/GCE'taki pik akımları ile karşılaştırıldığında, NGR/CKE'ta1.pik akımın 1.56 kat, 2.pik akımının ise 1.14 kat artı̆ğ görülmüştür. Nafyon fonksiyonel grupları ile grafeni stabilize ederek, grafit oluşumunu engeller ve grafenin eşşiz özelliklerinden (yüksek iletkenlik ve geniş yüzey alanı) dolayı N-GR/CKE, ETF'e karşı yüksek hassasiyet ve 
elektrokatalitik aktivite göstermiştir (Zhu ve ark., 2010; Er ve ark., 2016; Gao ve ark., 2016; Lu ve ark., 2018).

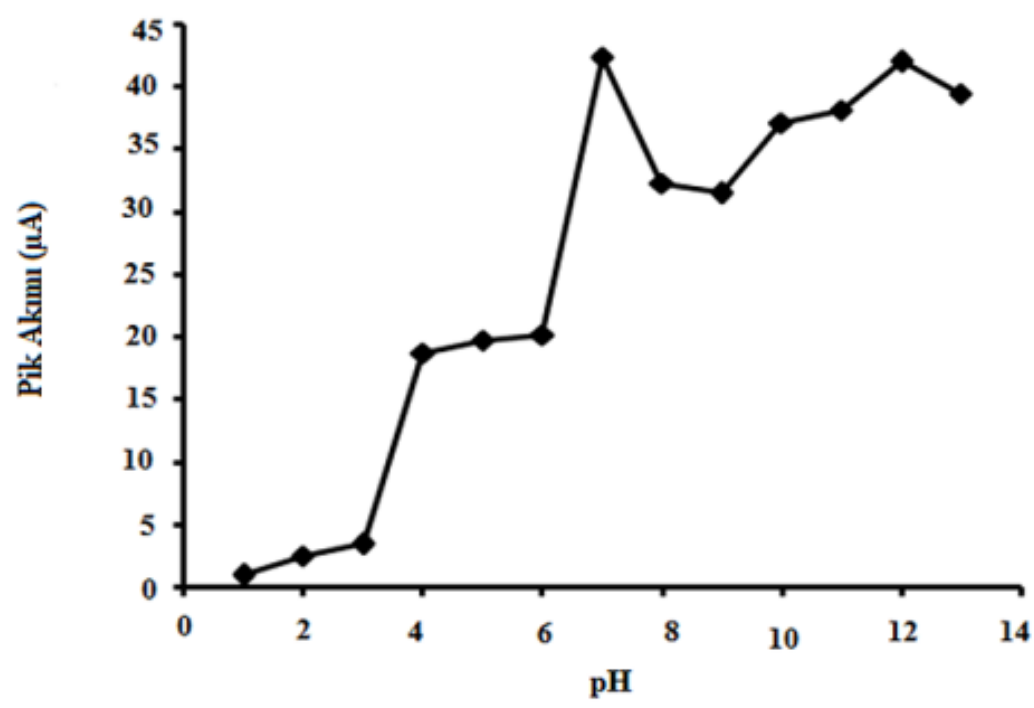

Şekil 1.1.0×10-4 M ETF'nin 1. pik akımına pH etkisi (CKE, DPV)

\section{ETF'nin CKE ve N-GR/CKE üzerinde yapılan DV çalışmaları}

ETF'nin CKE ve N-GR/CKE üzerinde elektrokimyasal davranışı DV yöntemiyle pH 7 fosfat tamponu içerisinde, önce $0 \mathrm{~V}^{\prime}$ dan başlayarak $-1,5 \mathrm{~V}$ kadar negatif yönde bir potansiyel taraması, daha sonra $-1.5 \mathrm{~V}$ başlayarak 0V'a pozitif yönde bir potansiyel taramasıyla incelenmiştir. Şekil 2'de ETF'nin CKE ve N-GR/CKE üzerinde farklı tarama hızlarında alınmış voltamogramları görülmektedir.

ETF'nin CKE ve N-GR/CKE üzerindeki davranışını incelemek için potansiyel tarama hızının $\operatorname{logaritmasının~}(\log v)$ pik akımının logaritmasına (logip) karşı $\log v$-logip grafikleri (her iki pik akımı için) çizilmiş ve doğrusal denklemler elde edilmiştir (Şekil 3). Bu grafiklerin eğimleri CKE ve NGR/CKE için sırasıyla şöyledir; 1.pik akımı için0.435; 0.764ve 2.pik akımı için 0.560; 0.501. Teorik olarak difüzyon kontrollü indirgemelerde $\log v$ 'ye karşı logip 0,5 iken, adsorpsiyon kontrollüde 0.1 olması beklenir (Laviron, E. 1979). CKE üzerinde ETF'nin birinci pik akımı ve ikinci pik akımı için oluşturulan $\log v$-logip grafiklerinde eğimlerin 0.5 yakınlığı ETF'nin elektrot yüzeyinde diffüzyon kontrolünde taşındığı göstermektedir. N-GR/GCE üzerinde birinci pik akımı için oluşturulan $\log v$ logip grafiğinin eğimi 0.5-1.0 arasında olması ETF'nin taşınmasında difüzyon yanında az miktarda adsorpsiyonunda olduğunu göstermektedir (Wang ve ark.,2006).

\section{ETFnin Voltametrik Tayini}

ETF'nin pik akımı ve konsantrasyonu arasındaki ilişki pH 7 fosfat tamponu içerisinde CKE ve N-GR/CKE üzerinde DPV yöntemiyle incelenmiştir. Bu elektrotlar kullanılarak ETF'nin çalışma aralığı, LOD, LOQ gün içi ve günler arası tekrar edilebilirliği 1.pik akımına göre değerlendirilmiştir.

CKE üzerinde farklı konsantrasyonda ETF'nin DPV'ları ve kalibrasyon doğrusu şekil 5 'te gösterilmiştir. Çalışma aralığı $1.51 \times 10^{-4}-1.76 \times 10^{-3} \mathrm{M}$ olarak hesaplanmıştır. 

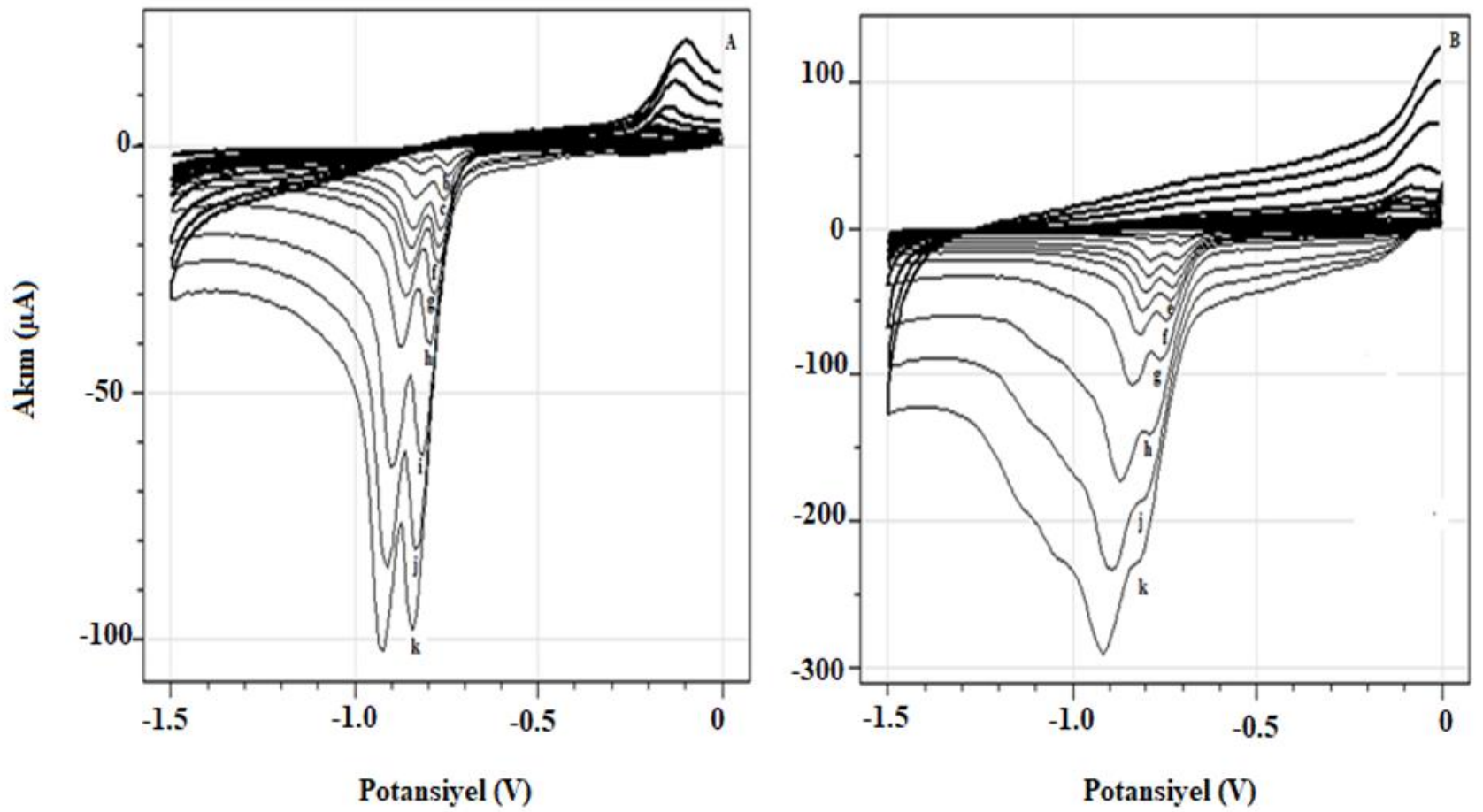

Şekil 2. a) $1.0 \times 10^{-4} \mathrm{M}$ ETF'nin GCE üzerinde $5-1000 \mathrm{mVs}^{-1}$ tarama hızı aralı̆̆ında alınan CV'leri b) $5.0 \times 10^{-5} \mathrm{M}$ ETF'nin N-GR/CKE üzerinde $5-1000 \mathrm{mVs}^{-1}$ tarama hızı aralığında alınan CV'leri (pH 7, tarama hizlar1; a)5, b)10, c)25, d)50, e) 75, f)100, g)150, h)250, 1)500, j)750, k)1000 $\mathrm{mVs}^{-1}$ )

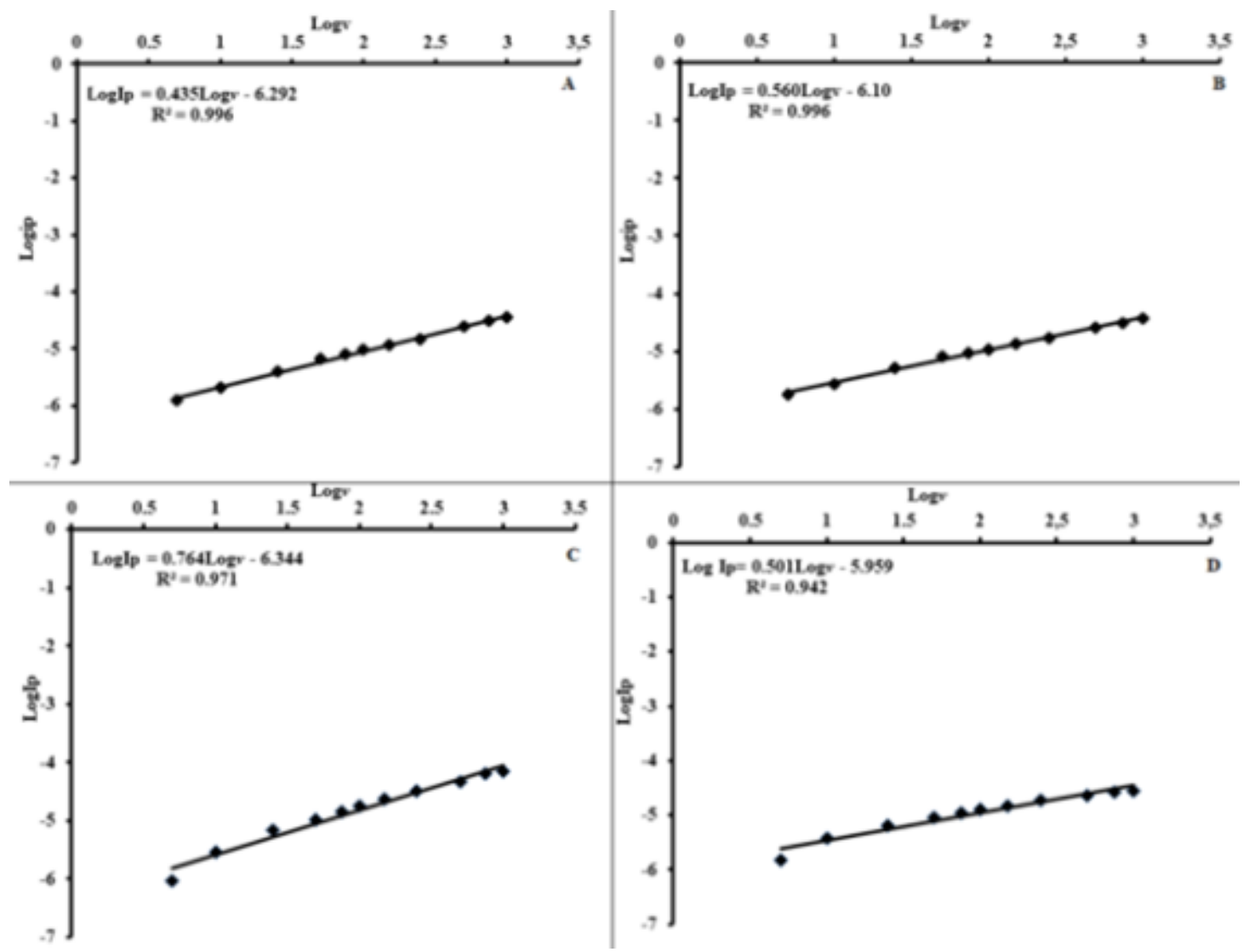

Şekil 3. $1.0 \times 10^{-4}$ M ETF'nin CKE üzerindekilogv - logip grafiği A) 1.pik akımı için, B) 2.pik akımı

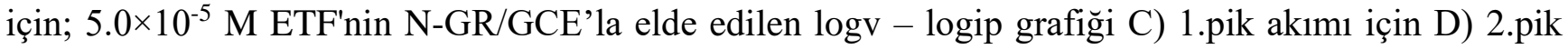
akımı için ( $\mathrm{pH}=7.0$ fosfat tamponunda $5-1000 \mathrm{mVs}^{-1}$ tarama hızında) 


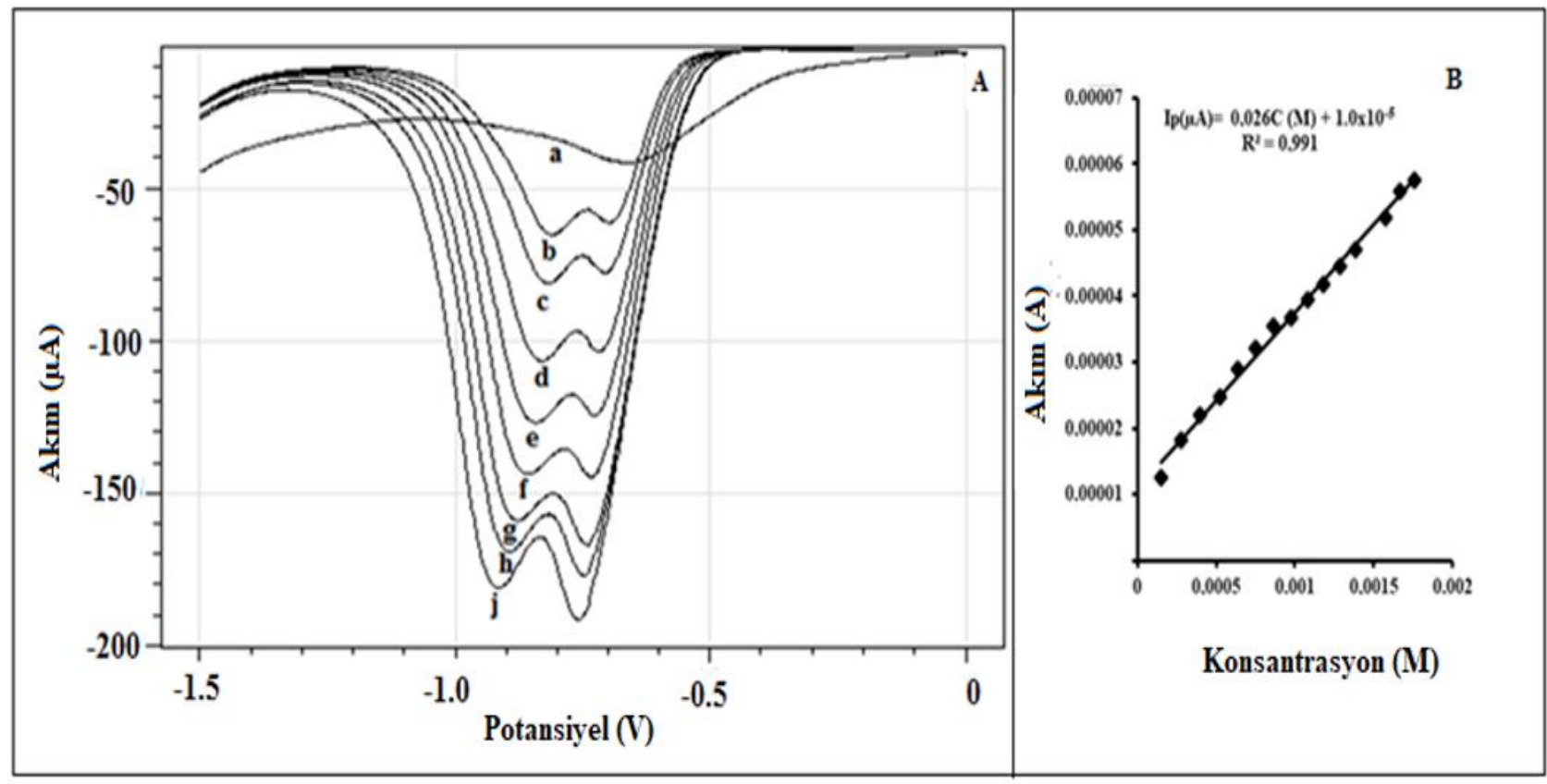

Şekil 4. A) Farklı konsantrasyonlardaki ETF'nin, CKE üzerinde $\mathrm{pH} 7$ fosfat tamponunda(\%25asetonitril) DPV yöntemiyle alınınan voltamogramları a)destek elektrolit b)2.78 $\times 10^{-}$ ${ }^{4} \mathrm{M}$ c) $\left.4.02 \times 10^{-4} \mathrm{M} \mathrm{d}\right) 6.04 \times 10^{-4} \mathrm{M}$ e) $\left.\left.\left.\left.8.64 \times 10^{-4} \mathrm{M} \mathrm{f}\right) 1.08 \times 10^{-3} \mathrm{M} \mathrm{g}\right) 1.29 \times 10^{-3} \mathrm{M} \mathrm{h}\right) 1.48 \times 10^{-3} \mathrm{M} \mathrm{j}\right) 1.76 \times 10^{-}$

${ }^{3} \mathrm{M}$; B) Konsantrasyona karşı pik akımı grafiği 1.pik akımı için

Analitik denklem aşağıdaki gibidir.

Ip $(\mu \mathrm{A})=0.0262 \mathrm{C}(\mathrm{M})+1.0 \times 10^{-5} R 2=0.991$ (1.pik akımı için)

Her iki elektrotta, gözlenebilme sınırı (LOD) 3s/m, tayin sınırı (LOQ ) $10 \mathrm{~s} / \mathrm{m}$ denklemleri kullanılarak hesaplanmıştır (Currie, 1999). Burada m kalibrasyon grafiğinin eğimini, s ise standart sapmadır. CKE üzerindeki çalışmalarda kalibrasyon grafiğindeki en düşük konsantrasyondan bir sonraki konsantrasyon olan $3.0 \times 10^{-4} \mathrm{M}$ ETF'nin, 5 ayrı hücrede 3'er kez tekrarlanan voltamogramları alınarak s hesaplandı. LOD ve LOQ değeri sırasıyla şöyledir: $2.28 \times 10^{-4} \mathrm{M} ; 7.62 \times 10^{-4} \mathrm{M} .3 .0 \times 10^{-4} \mathrm{M}$ ETF'nin pik akımı ve pik potansiyelinin günler arası ve gün içi tekrar edilebilirliği incelendi. ETF'nin günler arası pik akımının tekrar edilebilirliği \%BSS 4.08 iken, pik potansiyellerinin tekrar edilebilirliği, \% BSS 1.13'tür. ETF'nin gün içi pik akımının tekrar edilebilirliği \%BSS 3.98 iken, pik potansiyelinin tekrar edilebilirliği ise \% BSS 1.77 olarak hesaplanmıştır.

N-GR/CKE üzerinde farklı konsantrasyonlardaki ETF'nin DPV'ları ve kalibrasyon doğrusu şekil 5'de gösterilmiştir. ETF'nin N-GR/CKE üzerinde yapılan tayin çalışmalarında çalışma aralığı $6.86 \times 10^{-}$ ${ }^{4} \mathrm{M}-2.21 \times 10^{-3} \mathrm{M}$ olarak bulunmuştur. 


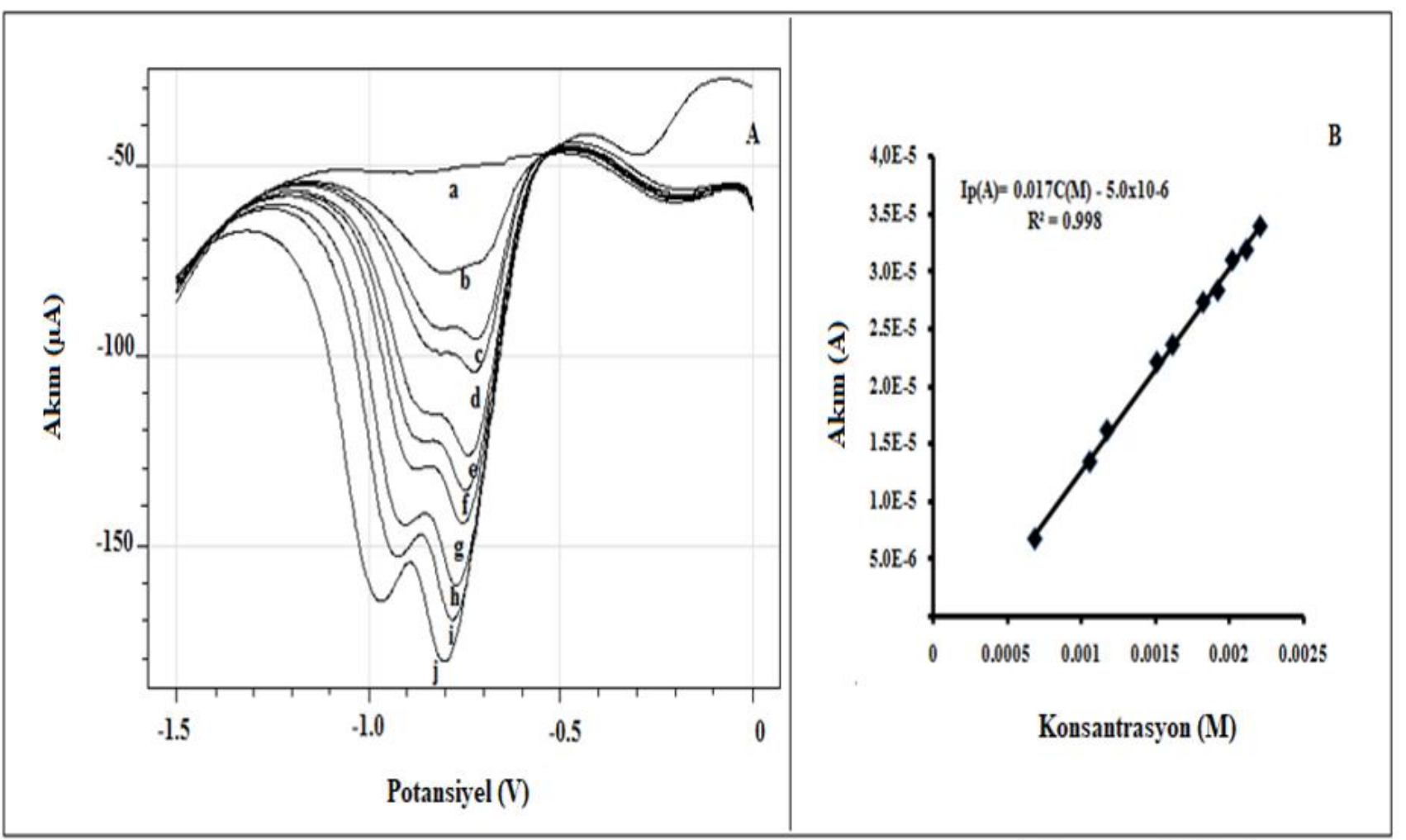

Şekil 5. A) Farklı konsantrasyonlardaki ETF'nin, N-GR/CKE üzerinde $p H 7$ fosfat tamponunda (\%25asetonitril) DPV yöntemiyle alınınan voltamogramları a)destek elektrolit b) $8.39 \times 10^{-5} \mathrm{M}$ c) $\left.6.86 \times 10^{-4} \mathrm{M} \mathrm{d}\right) 8.13 \times 10^{-4} \mathrm{M}$ e) $\left.\left.\left.\left.9.36 \times 10^{-4} \mathrm{M} \mathrm{f}\right) 1.06 \times 10^{-3} \mathrm{M} \mathrm{g}\right) 1.17 \times 10^{-3} \mathrm{M} \mathrm{h}\right) 1.51 \times 10^{-3} \mathrm{M} \mathrm{i}\right) 1.72 \times 10^{-3} \mathrm{M} \mathrm{j}$ ) $2.21 \times 10^{-3} \mathrm{M}$; B) Konsantrasyona karşı pik akımı grafiği 1.pik akımı için

Analitik denklem aşağıdaki gibidir.

$\operatorname{Ip}(\mu \mathrm{A})=0.017 \mathrm{C}(\mathrm{M})+5.0 \times 10^{-6} \quad R 2=0.998$

LOD ve LOQ değerindeki $\mathrm{s}$ değeri kalibrasyon grafiğindeki en düşük konsantrasyondan bir sonraki konsantrasyon olan 1,0x10-4 M ETF'nin, 5 ayrı hücrede 3'er kez tekrarlanan voltamogramlar1 alınarak hesaplanmıştır. LOD ve LOQ değerleri sırasıyla şöyledir:5.62×10 $0^{-5} \mathrm{M} ; 1.87 \times 10^{-4} \mathrm{M}$.

$1.0 \times 10^{-4} \mathrm{M}$ ETF'nin N-GR/CKE üzerindeki pik akımı ve pik potansiyelinin günler arası ve gün içi tekrar edilebilirliği incelenmiştir. Pik akımı ve pik potansiyelinin günler arası tekrar edilebilirliği sırasıyla \% BSS $1.15 ; 0.055$ 'tir. Pik akımı ve pik potansiyelinin gün içi tekrar edilebilirliği sırasıyla: \% BSS 2.51;2.10'dir.

\section{Girişim Etkisi}

ETF ile aynı ortamda bulunması muhtemelen bazı metal katyonların $\left(\mathrm{Cu}^{2+}, \mathrm{Ni}^{+2}, \mathrm{Co}^{2+}, \mathrm{Ca}^{2+}\right.$, $\left.\mathrm{Pb}^{2+}\right)$ girişim etkisi yöntemin şeçiciliğini ve doğruluğunu göstermek için incelenmiştir.

Girişim etkisi için $1.0 \times 10^{-4} \mathrm{M}$ ETF'nin varlığında girişim türlerinin ETF'nin konsantrasyonuna oranı 1:1 ve 1:5 olacak şekilde incelenmiştir. Girişim yapabilecek türler olmadığında elde edilen ETF'nin pik akımının, bu türlerin varlığında elde edilen pik akımına oranı \% geri kazanım şeklinde hesaplanmıştır. 
Çizelge 1. N-GR/CKE üzerindeki 1.0x10-4 M ETF'nin DPV ile tayininde bazı katyonların girişim etkisi ve $\%$ geri kazanım değerleri $(\mathrm{pH} 7)$

\begin{tabular}{|c|c|c|c|c|c|}
\hline $\begin{array}{c}\text { Girişim } \\
\text { Türleri } \\
(\mathbf{1 : 1 )}\end{array}$ & $\begin{array}{c}\text { \% Geri } \\
\text { Kazınım } \\
\text { (CKE) }\end{array}$ & $\begin{array}{c}\text { \% Geri } \\
\text { Kazınım } \\
(\mathrm{N}-\text { GR/CKE })\end{array}$ & $\begin{array}{c}\text { Girişim } \\
\text { Türleri } \\
(\mathbf{1 : 5 )}\end{array}$ & $\begin{array}{c}\% \text { Geri } \\
\text { Kazınım } \\
\text { (CKE) }\end{array}$ & $\begin{array}{c}\text { \% Geri } \\
\text { Kazınım } \\
(\text { N-GR/CKE ) }\end{array}$ \\
\hline $\mathrm{Cu}^{2+}$ & 101.6 & 93.9 & $\mathrm{Cu}^{2+}$ & 186.7 & 101 \\
\hline $\mathrm{Ni}^{+2}$ & 107 & 100 & $\mathrm{Ni}^{+2}$ & 146 & 101 \\
\hline $\mathrm{Co}^{2+}$ & 137 & 98.1 & $\mathrm{Co}^{2+}$ & 185 & 99.5 \\
\hline $\mathbf{C a}^{2+}$ & 125 & 98.5 & $\mathrm{Ca}^{2+}$ & 198 & 102 \\
\hline $\mathbf{P b}^{2+}$ & 109 & 98.8 & $\mathrm{~Pb}^{2+}$ & 106 & 104 \\
\hline
\end{tabular}

N-GR/CKE üzerindeki ETF'nin incelenen katyonlar varlığında etkilenmediği Çizelge 1'de açıkça görülmektedir. Bu sonuçlar N-GR/CKE üzerinde ETF'nin girişim etkisi incelenen katyonlar varlığında tayin edilebileceğini göstermektedir. CKE üzerinde ise ETF'nin $\mathrm{Cu}^{2+}(1: 1), \mathrm{Ni}^{2+}(1: 1) \mathrm{ve}^{2+} \mathrm{Pb}^{2+}(1: 1)(1: 5)$ katyonların varlığından etkilenmediği, fakat $\mathrm{Cu}^{2+}(1: 5), \mathrm{Ni}^{2+}(1: 5), \mathrm{Co}^{2+}(1: 1)(1: 5), \mathrm{Ca}^{2+}(1: 1)$ (1:5), $\mathrm{Pb}^{2+}(1: 1)$ (1:5) varlığında tayin edilemeyeceği görülmektedir. $\mathrm{Bu}$ sonuçlar N-GR/CKE üzerindeki ETF'nin tayini için önerilen yöntemin CKE üzerinde ETF'nin tayini için önerilen yönteme göre daha seçici olduğunu göstermektedir.

SONUÇ

Bu çalışmada ETF'nin CKE ve N-GR/CKE üzerinde DV yöntemiyle elektrokimyasal davranışı, DPV yöntemiyle elektrokimyasal tayini gerçekleştirilmiştir. Bu amaçla ETF'nin CKE ve N-GR/CKE üzerinde çalışma aralığı, LOD, LOQ, gün içi, günler arası tekrar edilebilirlik değerleri hesaplamıştır. ETF'nin N-GR/CKE üzerindeki çalışma aralığg $6.86 \times 10^{-4}-2.21 \times 10^{-3} \mathrm{M}$, LOD $5.62 \times 10^{-5} \mathrm{M}$, LOQ $1.87 \times 10^{-4} \mathrm{M}$, pik akımı ve pik potansiyelinin günler arası tekrar edilebilirliği sırasıyla \% BSS 1.15 ; 0.055, pik akımı ve pik potansiyelinin gün içi tekrar edilebilirliği sırasıyla: \% BSS 2.51; 2.10'dir. ETF'nin CKE ve N-GR/CKE üzerindeki tayinine girişim etkisi yapabilecek $\mathrm{Cu}^{2+}, \mathrm{Ni}^{2+}, \mathrm{Co}^{2+}, \mathrm{Ca}^{2+}$, $\mathrm{Pb}^{2+}$ gibi katyonların etkisi incelenmiştir. Burada ETF'nin N-GR/CKE üzerindeki tayin yönteminin CKE üzerindeki tayin yöntemine göre daha seçici olduğu görülmüştür. N-GR/CKE üzerinde ETF'nin basit, kolay, ucuz, hassas ve şeçici bir yöntemle tayini yapılmıştır. Sonuçlar bu yöntemin gerçek örneklerde ETF'nin tayini için kullanılabileceğini göstermektedir. Bunun yanında literatürde CKE ve N-GR/CKE üzerinde ETF'nin DPV yöntemiyle tayinine yönelik herhangi bir çalışmaya rastlanmamıştır.

\section{TEŞEKKÜR}

Prof. Dr. Hüseyin ÇELİKKAN'a vermiş olduğu katkılardan dolayı teşekkür ederim.

\section{Çıkar Çatışması}

Makaleye ait çalışmanın planlanması, yürütülmesi ve makalenin yazılması aşamalarında herhangi bir çıkar çatışması olmadığını beyan ederim.

\section{Yazar Katkısı}

Makalenin planlanması, yürütülmesi ve yazılması makale tek yazarı olarak tarafımca yapıldığı beyan ederim. 


\section{KAYNAKLAR}

Abdallah OI, 2020. Simultaneous determination of nine dinitroaniline herbicides in environmental samples using a validated vortex-assisted dispersive liquid-liquid microextraction procedure coupled with GC-MS/MS. Chemical Papers, 1-16.

Amir S, Jan MR, Shah J, 2019. Efficient environment friendly method for microextraction of dinitroaniline herbicides using supramolecular solvent. International Journal of Environmental Analytical Chemistry, 1-15.

Currie LA, 1999. International Recommendations Offered on Analytical Detection and Quantification Concepts and Nomenclature: Preamble, in Validation of Analytical Methods.

Er E, Çelikkan H, Erk N, 2016. Highly sensitive and selective electrochemical sensor based on highquality graphene/nafion nanocomposite for voltammetric determination of nebivolol. Sensors and Actuators B: Chemical, 224:170-177.

Gao F, Gao N, Nishitani A, Tanaka H, 2016. Rod-like hydroxyapatite and Nafion nanocomposite as an electrochemical matrix for simultaneous and sensitive detection of $\mathrm{Hg}^{2+}, \mathrm{Cu}^{2+}, \mathrm{Pb}^{2+}$ and $\mathrm{Cd}^{2+}$. Journal of Electroanalytical Chemistry, 775:212-218.

Geim, AK, Novoselov KS, 2010. Therise of graphene. In Nano science and technology: a collection of reviews from nature journals, 11-19.

Gerent GG, Santana ER, Martins EC, Spinelli A, 2021. A non-mercury electrode for the voltammetric determination of butralin in foods. Food Chemistry, 343, 128419.

Kalambate PK, Sanghavi BJ, Karna SP, Srivastava AK, 2015. Simultaneous voltammetric determination of paracetamol and domperidone based on a graphene/platinum nanoparticles/nafion composite modified glassy carbon electrode. Sensors and Actuators B: Chemical, 213, 285-294.

Kang X, Wang J, Wu H, Liu J, Aksay IA, Lin Y, 2010. A graphene-based electrochemical sensor for sensitive detection of paracetamol. Talanta, 81(3): 754-759.

Koçak B, Er E, Çelikkan, H, 2015. Stripping voltammetric analysis of dicofol on graphene-modified glassy carbon electrode. Ionics, 21(8): 2337-2344.

Laviron E, 1979. General expression of the linear potential sweep voltammogram in the case of diffusion less electrochemical systems. Journal of Electroanalytical Chemistry and Interfacial Electrochemistry, 101(1): 19-28.

Li J, Guo S, Zhai Y, Wang E, 2009. High-sensitivity determination of lead and cadmium based on the Nafion-graphene composite film. Analytica chimica acta, 649(2), 196-201.

Li J, Guo S, Zhai Y, Wang E, 2009. Nafion-graphene nanocomposite film as enhanced sensing platform for ultrasensitive determination of cadmium. Electrochemistry Communications, 11(5): 1085-1088.

Lu Y, Liang X, Niyungeko C, Zhou J, Xu J, Tian G, 2018. A review of the identification and detection of heavy metal ions in the environment by voltammetry. Talanta, 178: 324-338.

Novoselov KS, Geim AK, Morozov SV, Jiang D, Zhang Y, Dubonos SV, Firsov AA, 2004. Electric field effect in atomically thin carbon films. Science, 306(5696): 666-669.

Ntsendwana B, Mamba BB, Sampath S, Arotiba OA, 2012. Electrochemical detection of bisphenol A using graphene-modified glassy carbon electrode. International Journal of Electrochemical Science7(4), 3501-3512.

Pumera M, Ambrosi A, Bonanni A, Chng ELK, Poh HL,2010. Graphene for electrochemical sensing and biosensing. TrAC Trends in Analytical Chemistry, 29(9): 954-965. 
Saidi I, Soutrel I, Fourcade F, Amrane A, Bellakhal N, Geneste F, 2016. Electrocatalytic reduction of metronidazole using titanocene/Nafion ${ }^{\circledR}$-modified graphite felt electrode. ElectrochimicaActa, 191: 821-831.

Shackelford DD, McCormick RW, West SD, Turner LG, 2000. Determination of ethalfluralin in canola seed, meal, and refined oil by capillary gas chromatography with mass selective detection. Journal of Agricultural and Food Chemistry, 48(9): 4422-4427.

Thriveni T, Kumar JR, Lee JY, Sreedhar NY, 2009. Study of the voltammetric behaviour of the ethalfluralin and methalpropalin and its determination in environmental matrices at hanging mercury drop electrode. Environmental Monitoring andAssessment, 151(1-4): 9-18.

Wang CY, Wang X, Guan J, Hu XY, 2006. Voltammetric determination of meloxicam in pharmaceutical formulation and human serum at glassy carbon electrode modified by cysteic acid formed by electrochemical oxidation of Lcysteine. Sensors,6(9): 1139-1152

West SD, Weston JH, Day JREW, 1988. Gas chromatographic determination of residue levels of the herbicides trifluralin, benefin, ethalfluralin, and isopropalin in soi lwith confirmation by mass selective detection. Journal of theAssociation of Official Analytical Chemists, 71(6): 1082-1085.

Xia GH, Shen WJ, Wu B, Lu HY, Zhang R, Shen CY, Bian XH, 2014. Analysis of 7 dinitro aniline residues in complex food matrices by GC-NCI/MS. Chromatographia, 77(5-6): 493-499.

Yin H, Zhou Y, Ma Q, Ai S, Ju P, Zhu L, Lu L, 2010. Electrochemical oxidation behavior of guanine and adenine on graphene-Nafion composite film modified glassy carbon electrode and the simultaneous determination. Process Biochemistry, 45(10): 1707-1712.

Zhu Y, Murali S, Cai W, Li X, Suk JW, Potts JR, Ruoff, RS, 2010. Graphene and graphene oxide: synthesis, properties, and applications. Advanced Materials, 22(35): 3906-3924. 